\title{
TEMPORAL TRENDS IN CARDIOGENIC SHOCK COMPLICATING ACUTE MYOCARDIAL INFARCTION
}

\author{
Robert J. Goldberg, Ph.D., Navid A. Samad, M.B., B.S., M.P.H., Jorge Yarzebski, M.D., M.P.H., \\ Jerry Gurwitz, M.D., Carol Bigelow, Ph.D., and Joel M. Gore, M.D.
}

\begin{abstract}
Background Limited information is available on trends in the incidence of and mortality due to cardiogenic shock complicating acute myocardial infarction. We studied the incidence of cardiogenic shock complicating acute myocardial infarction and in-hospital death rates among patients with this condition in a single community from 1975 through 1997.

Methods We conducted an observational study of 9076 residents of metropolitan Worcester, Massachusetts, who were hospitalized with confirmed acute myocardial infarction in all local hospitals during 11 one-year periods between 1975 and 1997. Our study included periods before and after the advent of reperfusion therapy.

Results The incidence of cardiogenic shock remained relatively stable over time, averaging 7.1 percent among patients with acute myocardial infarction. The results of a multivariable regression analysis indicated that the patients hospitalized during recent study years were not at a substantially lower risk for shock than patients hospitalized in the mid-to-late 1970s. Patients in whom cardiogenic shock developed had a significantly greater risk of dying during hospitalization (71.7 percent) than those who did not have cardiogenic shock (12.0 percent, $\mathrm{P}<0.001)$. A significant trend toward an increase in in-hospital survival among patients with cardiogenic shock in the mid-to-late 1990s was found in crude and adjusted analyses.
\end{abstract}

Conclusions Our findings indicate no significant change in the incidence of cardiogenic shock complicating acute myocardial infarction over a 23-year period. However, the short-term survival rate has increased in recent years at the same time as the use of coronary reperfusion strategies has increased. (N Engl J Med 1999;340:1162-8.)

(C)1999, Massachusetts Medical Society.

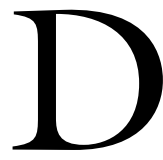
ESPITE recent advances in the care of patients with acute coronary disease and the benefits associated with the early use of reperfusion strategies, cardiogenic shock as a complication of acute myocardial infarction continues to be associated with a dismal prognosis., ${ }^{1,2}$ With improvements in electrocardiographic monitoring and the treatment of life-threatening ventricular arrhythmias, cardiogenic shock has emerged as the most common cause of death among patients admitted to the hospital with acute myocardial infarction. ${ }^{3}$ The incidence of cardiogenic shock complicating acute myocardial infarction ranges from 5 to 15 percent. ${ }^{1,4-10}$ Population-based estimates of changes over time in the incidence of cardiogenic shock remain limited ${ }^{11}$; the majority of data about either the incidence of cardiogenic shock or the prognosis associated with this complication have been derived from single hospitals and specialty referral centers or in the context of post hoc analyses of randomized trials. Because there is no definitive treatment to reestablish blood flow in the infarct-related coronary artery, the in-hospital death rate associated with cardiogenic shock exceeds 65 percent ${ }^{4,10,12-15}$; from the mid-1970s through the late 1980s, there was little change in the mortality rate associated with this clinical syndrome. ${ }^{11}$

A growing trend has been to use more aggressive therapeutic interventions early in patients who have cardiogenic shock as a result of acute myocardial infarction. ${ }^{16}$ In the current era of research on cost effectiveness and outcomes and of aggressive efforts to limit infarct size and maintain left ventricular function, it remains important to study trends in the incidence of cardiogenic shock complicating acute myocardial infarction and in case fatality rates and to study the possible effect of new treatment strategies.

We undertook a communitywide study in order to extend the findings of a report on temporal trends (for the period from 1975 through 1988) in the incidence of cardiogenic shock and in-hospital death rates among patients with confirmed acute myocardial infarction who had been admitted to all hospitals in metropolitan Worcester, Massachusetts. ${ }^{11}$ The earlier study predated the use of thrombolytic agents and the increasing use of myocardial-revascularization approaches in patients with acute coronary disease. The current findings are based on data on 9076 residents of the Worcester metropolitan area who had acute myocardial infarction and were admitted to hospitals in greater Worcester from 1975 through 1997.

\section{METHODS}

\section{Study Population}

The study population consisted of residents of metropolitan Worcester who were assigned a diagnosis of acute myocardial infarction at discharge from 1 of the 16 teaching and community hospitals (the number of hospitals became smaller during the

From the Department of Medicine, University of Massachusetts Medical School, Worcester (R.J.G., J.Y., J.G., J.M.G.); and the Department of Biostatistics and Epidemiology, School of Public Health and Health Sciences, University of Massachusetts, Amherst (N.A.S., C.B.). Address reprint requests to Dr. Goldberg at the Department of Medicine, Division of Cardiovascular Medicine, University of Massachusetts Medical School, 55 Lake Ave. N., Worcester, MA 01655, or at robert.goldberg@ummc.ummed.edu. 
course of the study as a result of hospital mergers and consolidations) in the standard metropolitan statistical area (1990 population, 437,000) during 1975, 1978, 1981, 1984, 1986, 1988, 1990, $1991,1993,1995$, and 1997.17-19 The medical records of all potentially eligible patients were reviewed and the diagnosis was confirmed according to preestablished criteria. ${ }^{17-19}$

Cardiogenic shock was defined as a systolic blood pressure of less than $80 \mathrm{~mm} \mathrm{Hg}$ in the absence of hypovolemia and associated with cyanosis, cold extremities, changes in mental status, persistent oliguria, or congestive heart failure. ${ }^{11}$ The definition of cardiogenic shock remained the same in all periods studied; the disorder was defined in the study so that patients with classic signs and symptoms of this clinical syndrome would be included.

\section{Data Collection}

From the hospital records of patients with validated acute myocardial infarction, we abstracted demographic, medical-history, and clinical data as well as information about the use of therapeutic interventions and specialized procedures. ${ }^{17-21}$ Data regarding the use of thrombolytic agents, coronary-artery bypass grafting, and percutaneous transluminal coronary angioplasty were included as these therapies became available in clinical practice.

\section{Statistical Analysis}

Differences in the distribution of characteristics between patients with cardiogenic shock and those without, and between patients with shock who survived to be discharged from the hospital and those who did not, were studied with the use of chi-square tests for categorical variables and t-tests for continuous variables, as appropriate. All tests of statistical significance were two-tailed. Multivariable logistic-regression models were used to assess the significance of temporal trends in the incidence of cardiogenic shock while controlling for potentially confounding demographic, medical-history, and clinical factors. Control variables included indicators for the following: age, male sex, history of various coexisting disorders (angina, diabetes, hypertension, or stroke), and type of acute myocardial infarction (initial vs. recurrent, Q-wave vs. nonQ-wave, and anterior vs. inferior or posterior).

Because of the observational, nonrandomized nature of this study, and because of our methods of data collection, which did not allow us to determine whether a medical therapy or surgical intervention preceded or came after the occurrence of cardiogenic shock, we did not control for the use of various interventional procedures (cardiac catheterization, coronary-artery bypass grafting, or percutaneous transluminal coronary angioplasty) or medical therapies (such as thrombolytic agents). Another reason that we did not control for these practices is the difficulty of interpreting any observed adjusted estimates of association. Our approach to model building focused on the hypothesis that variations in the incidence of cardiogenic shock over time were the result of changes in the demographic or clinical characteristics (or both) of the study sample. We recognize that these trends might also reflect improvements in the use of various approaches to care and increasing use of these approaches - over time.

We studied the effect of cardiogenic shock on in-hospital death rates by calculating in-hospital case fatality rates. Multivariable logistic-regression analyses were carried out to assess the effect of cardiogenic shock on mortality during hospitalization and to study changes over time in the in-hospital case fatality rates associated with cardiogenic shock while controlling for potentially confounding factors. This approach to model development was similar to that described for the end point of cardiogenic shock.

\section{RESULTS}

\section{Base-Line Characteristics}

During all the study years combined, the patients with cardiogenic shock were significantly older than those who did not have this complication (Table 1).
Table 1. Characteristics of Patients

With ACUTE Myocardial INFARCTION ACCORDING TO the Presence or Absence of Cardiogenic Shock.

\begin{tabular}{|c|c|c|c|}
\hline Characteristic & $\begin{array}{c}\text { SHоск } \\
\text { PrESENT } \\
(\mathrm{N}=644)\end{array}$ & $\begin{array}{c}\text { SHOCK } \\
\text { ABSENT } \\
(\mathbf{N}=\mathbf{8 4 3 2})\end{array}$ & $\underset{\text { VALUe }}{\mathbf{P}}$ \\
\hline Mean age (yr) & 71.6 & 67.7 & $<0.001$ \\
\hline Male sex $(\%)$ & 50.8 & 60.3 & $<0.001$ \\
\hline \multicolumn{4}{|l|}{ Coexisting conditions (\%) } \\
\hline Angina & 27.5 & 26.9 & 0.76 \\
\hline Diabetes & 28.9 & 25.4 & $<0.05$ \\
\hline Hypertension & 51.2 & 51.5 & 0.91 \\
\hline Stroke & 12.1 & 8.4 & $<0.001$ \\
\hline \multicolumn{4}{|l|}{ Type of myocardial infarction (\%) } \\
\hline Initial & 60.2 & 65.7 & $<0.005$ \\
\hline Q-wave & 68.1 & 49.1 & $<0.001$ \\
\hline Anterior & 52.6 & 44.8 & $<0.001$ \\
\hline \multicolumn{4}{|l|}{ Procedures $(\%)$} \\
\hline Cardiac catheterization & 23.1 & 20.2 & 0.08 \\
\hline Coronary-artery bypass surgery* & 7.4 & 3.1 & $<0.001$ \\
\hline Intraaortic balloon counterpulsation & 20.0 & 1.5 & $<0.001$ \\
\hline $\begin{array}{l}\text { Percutaneous transluminal coronary } \\
\text { angioplasty* }\end{array}$ & 16.1 & 7.9 & $<0.001$ \\
\hline Use of thrombolytic agents $(\%)^{*}$ & 22.8 & 21.6 & 0.59 \\
\hline
\end{tabular}

*Data were available only for the period from 1986 to 1997.

A significantly greater proportion of the patients who had cardiogenic shock were women, had a history of diabetes or stroke, and had acute myocardial infarction that was recurrent, Q-wave in type, and anterior in location. Patients with cardiogenic shock were significantly more likely to undergo coronary-artery bypass grafting, intraaortic balloon counterpulsation, and percutaneous transluminal coronary angioplasty than those without shock. From the mid-1980s until the late 1990s, thrombolytic therapy was used in slightly less than one quarter of patients, irrespective of the presence or absence of cardiogenic shock.

Table 2 summarizes changes in the characteristics of patients in whom cardiogenic shock developed or did not develop over the 23-year period under study. The characteristics are categorized in five periods combining two years each and one single-year period to make analyses of the data easier to interpret and to coincide with changes in the care of patients with acute myocardial infarction. Over time, patients with acute myocardial infarction were increasingly older, more likely to have selected coexisting conditions, and more likely to have a non-Q-wave myocardial infarction. The use of thrombolytic therapy, cardiac catheterization, percutaneous transluminal coronary angioplasty, and coronary-artery bypass grafting increased over time among all patients; the use of myocardial-revascularization techniques increased markedly during the mid-to-late 1990s. An increasing proportion of the patients with cardiogenic shock presented with an initial acute myocardial infarction over time. Over the 23-year study period, the use of intraaortic balloon counterpulsation increased dramatically among patients with cardiogenic shock. 
Table 2. Temporal Trends in the Characteristics of Patients with Acute Myocardial Infarction According to the Presence or Absence of Cardiogenic Shock.

\begin{tabular}{|c|c|c|c|c|c|c|c|c|c|c|c|c|c|c|}
\hline \multirow[t]{2}{*}{ ChARACTERISTIC* } & \multicolumn{2}{|c|}{1975 AND 1978} & \multicolumn{2}{|c|}{1981 AND 1984} & \multicolumn{2}{|c|}{1986 AND 1988} & \multicolumn{2}{|c|}{1990 AND 1991} & \multicolumn{2}{|c|}{1993 AND 1995} & \multicolumn{2}{|c|}{1997} & \multicolumn{2}{|c|}{$\begin{array}{l}\text { P VALUE } \\
\text { FOR TREND }\end{array}$} \\
\hline & $\begin{array}{l}\text { SHOCK } \\
\text { PRESENT } \\
(\mathrm{N}=117)\end{array}$ & $\begin{array}{c}\text { SHOCK } \\
\text { ABSENT } \\
(\mathrm{N}=1509)\end{array}$ & $\begin{array}{c}\text { SHOCK } \\
\text { PRESENT } \\
(\mathrm{N}=123)\end{array}$ & $\begin{array}{c}\text { SHOCK } \\
\text { ABSENT } \\
(\mathrm{N}=1589)\end{array}$ & $\begin{array}{l}\text { SHOCK } \\
\text { PRESENT } \\
(\mathrm{N}=118)\end{array}$ & $\begin{array}{c}\text { SHOCK } \\
\text { ABSENT } \\
(\mathrm{N}=1306)\end{array}$ & $\begin{array}{l}\text { SHOCK } \\
\text { PRESENT } \\
(\mathrm{N}=89)\end{array}$ & $\begin{array}{c}\text { SHOCK } \\
\text { ABSENT } \\
(\mathrm{N}=1424)\end{array}$ & $\begin{array}{c}\text { SHOCK } \\
\text { PRESENT } \\
(\mathrm{N}=126)\end{array}$ & $\begin{array}{c}\text { SHOCK } \\
\text { ABSENT } \\
(\mathrm{N}=1668)\end{array}$ & $\begin{array}{l}\text { SHOCK } \\
\text { PRESENT } \\
(\mathrm{N}=71)\end{array}$ & $\begin{array}{c}\text { SHOCK } \\
\text { ABSENT } \\
(\mathrm{N}=936)\end{array}$ & $\begin{array}{l}\text { SHOCK } \\
\text { PRESENT }\end{array}$ & $\begin{array}{l}\text { SHOCK } \\
\text { ABSENT }\end{array}$ \\
\hline Mean age (yr) & 70 & 65 & 70 & 67 & 74 & 67 & 74 & 69 & 72 & 69 & 71 & 70 & $<0.06$ & $<0.001$ \\
\hline Male sex (\%) & 48 & 63 & 59 & 62 & 47 & 61 & 51 & 57 & 48 & 59 & 52 & 58 & 0.78 & $<0.001$ \\
\hline \multicolumn{15}{|l|}{$\begin{array}{l}\text { Coexisting con- } \\
\text { ditions (\%) }\end{array}$} \\
\hline Angina & 21 & 25 & 29 & 29 & 31 & 26 & 33 & 27 & 25 & 28 & 28 & 25 & 0.56 & 0.77 \\
\hline Diabetes & 29 & 22 & 25 & 22 & 25 & 25 & 25 & 26 & 40 & 27 & 27 & 33 & 0.23 & $<0.001$ \\
\hline Hypertension & 44 & 41 & 40 & 51 & 44 & 49 & 58 & 53 & 65 & 57 & 62 & 60 & $<0.001$ & $<0.001$ \\
\hline Stroke & 9 & 5 & 11 & 8 & 13 & 8 & 17 & 9 & 11 & 10 & 14 & 11 & 0.30 & $<0.001$ \\
\hline \multicolumn{15}{|l|}{ Type of MI (\%) } \\
\hline Initial & 57 & 67 & 55 & 65 & 61 & 69 & 52 & 67 & 66 & 62 & 73 & 64 & $<0.025$ & $<0.05$ \\
\hline Q wave & 85 & 67 & 81 & 58 & 64 & 51 & 58 & 46 & 55 & 36 & 63 & 32 & $<0.001$ & $<0.001$ \\
\hline Anterior & 52 & 51 & 56 & 52 & 57 & 49 & 56 & 42 & 48 & 35 & 46 & 37 & 0.29 & $<0.001$ \\
\hline \multicolumn{15}{|l|}{ Procedures (\%) } \\
\hline $\begin{array}{c}\text { Cardiac cathe- } \\
\text { terization }\end{array}$ & 5 & 2 & 7 & 7 & 12 & 25 & 25 & 21 & 49 & 35 & 52 & 39 & $<0.001$ & $<0.001$ \\
\hline CABG & - & - & - & 1 & 3 & 2 & 3 & 2 & 10 & 4 & 14 & 5 & $<0.001$ & $<0.001$ \\
\hline IBCP & 5 & 0 & 5 & 1 & 13 & 2 & 16 & 2 & 46 & 2 & 42 & 3 & $<0.001$ & $<0.001$ \\
\hline PTCA & - & - & - & - & 2 & 3 & 7 & 4 & 29 & 12 & 28 & 14 & $<0.001$ & $<0.001$ \\
\hline $\begin{array}{l}\text { Use of throm- } \\
\text { bolytic } \\
\text { agents (\%) }\end{array}$ & - & - & - & - & 8 & 15 & 26 & 25 & 33 & 25 & 25 & 20 & $<0.001$ & $<0.001$ \\
\hline
\end{tabular}

* MI denotes myocardial infarction, CABG coronary-artery bypass grafting, IBCP intraaortic balloon counterpulsation, and PTCA percutaneous transluminal coronary angioplasty.

\section{Incidence of Cardiogenic Shock}

The incidence of cardiogenic shock remained relatively stable over the initial decade of this study; incidence peaked in 1988, after which there was an inconsistent decline in the proportion of patients with shock. The overall incidence of cardiogenic shock averaged 7.1 percent over the 23 -year study period (Fig. 1).

We carried out two regression analyses to study changes over time in the incidence of cardiogenic shock while adjusting for various potentially confounding factors (Table 3 ). After controlling for age, sex, and history of cardiovascular disease, we found nonsignificant trends in the multivariable-adjusted risk of shock over the period under study - results similar to the unadjusted findings (Table 3 ). After controlling for age, sex, medical history, and characteristics of acute myocardial infarction, we found that the risk of cardiogenic shock also did not change significantly over time.

\section{In-Hospital Case Fatality Rates}

Patients with acute myocardial infarction in whom cardiogenic shock developed had significantly higher in-hospital case fatality rates overall (71.7 percent, vs. 12.0 percent among those without shock; $\mathrm{P}<0.001)$ and during each of the periods under study (Fig. 2). The in-hospital death rates among the patients with cardiogenic shock remained relatively constant until

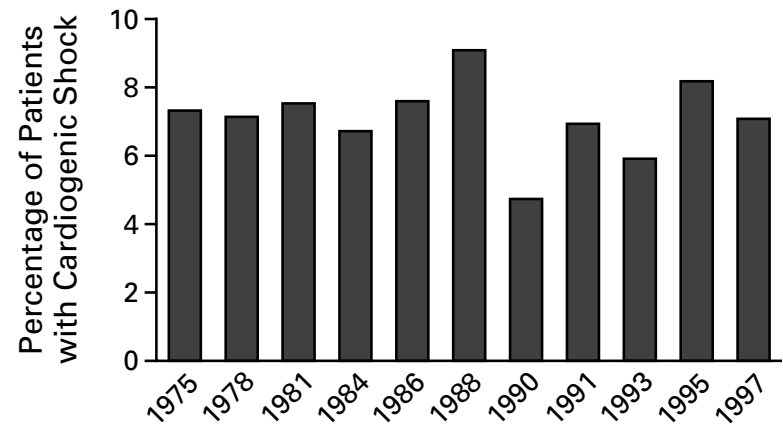

Figure 1. Temporal Trends in the Incidence of Cardiogenic Shock in Patients with Acute Myocardial Infarction.

the mid-to-late 1990s, averaging approximately 77 percent; 61 percent of patients with cardiogenic shock died in 1993 and 1995 and 59 percent in 1997.

A logistic-regression analysis was carried out to control simultaneously for age, sex, medical history, and characteristics of acute myocardial infarction in determining the association between the occurrence of cardiogenic shock and in-hospital mortality. This analysis confirmed the markedly higher risk of inhospital death among patients who had cardiogenic shock, as compared with those who did not (adjusted odds of dying, 21.0; 95 percent confidence interval, 17.2 to 25.6) for the combined study periods. A 
Table 3. Temporal Trends in the Crude and Multivariable-Adjusted Odds of Cardiogenic Shock in Patients with Acute Myocardial infarction.

\begin{tabular}{|c|c|c|c|c|}
\hline \multirow[t]{2}{*}{ Study Period and Years } & $\begin{array}{l}\text { PeRCENTAGE } \\
\text { OF PATIENTS } \\
\text { WITH SHOCK }\end{array}$ & $\begin{array}{l}\text { Without } \\
\text { ADJUSTMENT }\end{array}$ & FIRST ADJUSTMENT & SeCond AdJustment \\
\hline & \multicolumn{4}{|c|}{ odds ratio $(95 \%$ confidence interval)* } \\
\hline $\begin{array}{l}\text { Mid-to-late 1970s } \\
\quad(1975 \text { and 1978) } \dagger\end{array}$ & 7.2 & 1.0 & 1.0 & 1.0 \\
\hline $\begin{array}{l}\text { Early 1980s } \\
\quad(1981 \text { and 1984) }\end{array}$ & 7.2 & $1.00(0.77-1.30)$ & $0.95(0.73-1.23)$ & $0.99(0.75-1.31)$ \\
\hline $\begin{array}{l}\text { Mid-to-late 1980s } \\
\text { (1986 and 1988) }\end{array}$ & 8.3 & $1.17(0.89-1.52)$ & $1.10(0.84-1.43)$ & $1.23(0.92-1.63)$ \\
\hline $\begin{array}{l}\text { Early 1990s } \\
\quad(1990 \text { and 1991) }\end{array}$ & 5.9 & $0.81(0.61-1.07)$ & $0.73(0.55-0.98)$ & $0.94(0.70-1.26)$ \\
\hline $\begin{array}{l}\text { Mid-1990s } \\
\text { (1993 and 1995) }\end{array}$ & 7.0 & $0.97(0.75-1.27)$ & $0.89(0.68-1.15)$ & $1.27(0.96-1.68)$ \\
\hline Late 1990s (1997) & 7.1 & $0.98(0.72-1.33)$ & $0.87(0.64-1.18)$ & $1.31(0.95-1.80)$ \\
\hline
\end{tabular}

* The odds ratio was adjusted initially for age, sex, and medical history. The second adjustment was for age, sex, medical history, and the order (initial vs. recurrent), type, and location of the acute myocardial infarction.

†This was the reference category.

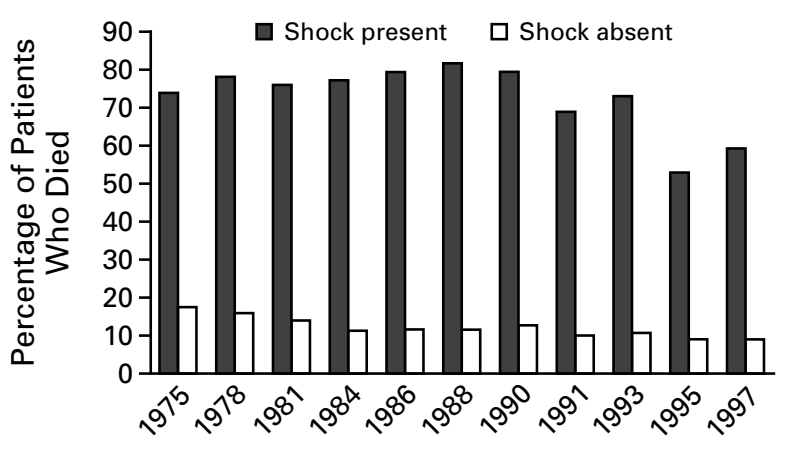

Figure 2. Temporal Trends in In-Hospital Death Rates among Patients with Acute Myocardial Infarction According to the Presence or Absence of Cardiogenic Shock.

similar adverse effect of cardiogenic shock on inhospital death rates was found when this analysis was restricted to patients in whom shock developed over the period of increasing use of myocardial-reperfusion strategies (1986 through 1997).

As in the analysis of trends over time in the incidence of cardiogenic shock, we performed two separate multivariable regression analyses to evaluate changes over time in in-hospital mortality of patients with cardiogenic shock while controlling for previously described prognostic characteristics. The results suggested considerable improvements in the in-hospital survival of patients with shock, particularly during the 1990s (Table 4). Depending on the covariates adjusted for, the risk of dying from cardiogenic shock was markedly lower in the mid-tolate 1990s than in the two previous decades.
The patients with cardiogenic shock who survived to discharge were significantly younger than those who did not survive (Table 5 ). The patients who survived were significantly more likely to have received angiotensin-converting-enzyme inhibitors, antiplatelet agents, beta-blockers, digoxin, and thrombolytic agents. Patients who died from this complication were less likely to have undergone coronary-artery bypass grafting, percutaneous transluminal coronary angioplasty, or intraaortic balloon counterpulsation.

\section{DISCUSSION}

The results of this population-based study suggest a relatively constant incidence of cardiogenic shock over the 23-year period under study; a significantly higher in-hospital death rate among patients in whom shock developed; and improvement over time in the in-hospital survival rate of patients with cardiogenic shock, particularly during the mid-to-late 1990s.

The incidence of cardiogenic shock after acute myocardial infarction ranges from 5 to 15 percent in published studies., ${ }^{1,-11}$ This relatively wide range reflects, in part, the varying definitions of acute myocardial infarction and cardiogenic shock, the use of representative as opposed to more highly selected patient samples, and the rates of use of therapeutic options that may reduce the risk of cardiogenic shock. The overall incidence of cardiogenic shock in the current study falls within this range. In the worldwide Global Utilization of Streptokinase and Tissue Plasminogen Activator for Occluded Coronary Arteries (GUSTO-1) randomized trial, cardiogenic shock developed in 7.2 percent of approximately 41,000 patients with acute myocardial infarction. ${ }^{22}$ 
Table 4. Temporal Trends in the Crude and Multivariable-Adjusted Odds of In-Hospital Death among Patients with Cardiogenic Shock Complicating ACUTE Myocardial Infarction.

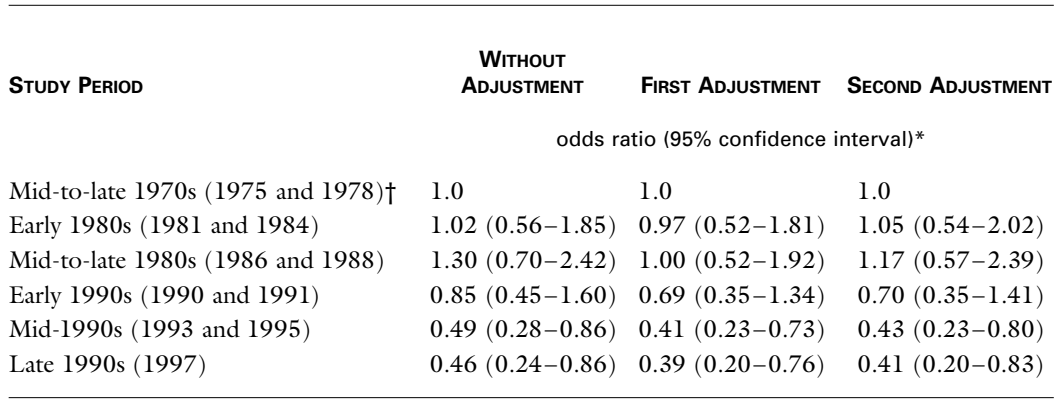

*The odds ratio was adjusted initially for age, sex, and medical history. The second adjustment was for age, sex, medical history, and the order (initial vs. recurrent), type, and location of the acute myocardial infarction.

$\dagger$ This was the reference category.

In GUSTO-1, patients treated with accelerated recombinant tissue plasminogen activator were significantly less likely to have shock; this finding suggests the possible benefit of early reperfusion that is associated with the use of this thrombolytic regimen. ${ }^{22}$

We have previously documented progressive declines since the mid-1970s in the in-hospital death rates of patients with acute myocardial infarction. ${ }^{17-19,23}$ We have also found declines in the rates of out-ofhospital death attributed to coronary heart disease. ${ }^{24}$ Therefore, it is possible that the patients who make it to the hospital and in whom cardiogenic shock subsequently develops are sicker, and thus at greater risk, than those who do not; this explains in part some of the nonsignificant changes in the incidence of cardiogenic shock that were found. Because of the nonrandomized nature of the current study, we could not address directly the association between the increased use of thrombolytic agents and surgical interventions and the risk of shock.

Patients should be encouraged to seek medical care as soon as possible after having symptoms of acute myocardial infarction, because immediate care may reduce the incidence of cardiogenic shock and the associated mortality. Efforts to decrease the incidence of cardiogenic shock should focus on identifying patients who are at high risk for this complication and instructing them to seek care immediately after the onset of acute coronary symptoms so that appropriate monitoring, risk stratification, and intervention can be undertaken. ${ }^{25}$ Aggressive intervention may result in improved survival rates among patients in whom cardiogenic shock has developed, because the early detection of precursors of shock or signs of circulatory failure are likely to result in increased and timely intervention.

Patients in whom cardiogenic shock has developed
Table 5. Characteristics of Patients With Cardiogenic Shock Complicating ACUTe Myocardial Infarction ACCORding to Whether They Survived to Discharge OR DiEd IN THE Hospital.

\begin{tabular}{|c|c|c|c|}
\hline Characteristic & $\begin{array}{l}\text { SURVIVED } \\
(\mathrm{N}=182)\end{array}$ & $\begin{array}{c}\text { DIED } \\
(\mathrm{N}=\mathbf{4 6 2})\end{array}$ & $\begin{array}{c}P \\
\text { VALUE }\end{array}$ \\
\hline Mean age (yr) & 66.2 & 73.7 & $<0.001$ \\
\hline \multicolumn{4}{|l|}{ Age $(\%)$} \\
\hline$<55 \mathrm{yr}$ & 18.1 & 4.1 & \\
\hline $55-64 \mathrm{yr}$ & 24.7 & 16.2 & $<0.001$ \\
\hline $65-74 \mathrm{yr}$ & 30.8 & 28.8 & \\
\hline$\geqslant 75 \mathrm{yr}$ & 26.4 & 50.9 & \\
\hline Male sex $(\%)$ & 51.7 & 50.4 & 0.78 \\
\hline \multicolumn{4}{|l|}{ Coexisting conditions (\%) } \\
\hline Angina & 24.2 & 28.8 & 0.24 \\
\hline Diabetes & 28.0 & 29.2 & 0.76 \\
\hline Hypertension & 51.7 & 51.1 & 0.90 \\
\hline Stroke & 9.9 & 13.0 & 0.28 \\
\hline \multicolumn{4}{|l|}{ Myocardial infarction (\%) } \\
\hline Initial & 63.2 & 59.0 & 0.33 \\
\hline Q wave & 66.9 & 68.6 & 0.68 \\
\hline Anterior & 49.1 & 54.0 & 0.28 \\
\hline \multicolumn{4}{|l|}{ Medications } \\
\hline $\begin{array}{l}\text { Angiotensin-converting-enzyme } \\
\text { inhibitors* }\end{array}$ & 76.5 & 31.5 & $<0.001$ \\
\hline Antiplatelet agents & 55.5 & 37.0 & $<0.001$ \\
\hline Beta-blockers & 51.1 & 33.1 & $<0.001$ \\
\hline Calcium-channel blockers & 41.6 & 44.1 & 0.64 \\
\hline Digoxin & 62.1 & 48.7 & $<0.005$ \\
\hline Thrombolytic agents $\dagger$ & 33.6 & 17.9 & $<0.001$ \\
\hline \multicolumn{4}{|l|}{ Procedures } \\
\hline Coronary-artery bypass surgery $†$ & 14.4 & 4.3 & $<0.001$ \\
\hline Intraaortic balloon counterpulsation & 33.5 & 14.7 & $<0.001$ \\
\hline $\begin{array}{l}\text { Percutaneous transluminal coronary } \\
\text { angioplasty }\end{array}$ & 32.0 & 9.0 & $<0.001$ \\
\hline
\end{tabular}

*Data were available only for the period from 1990 to 1995. †Data were available only for the period from 1986 to 1995. 
continue to have a markedly higher risk of dying in the hospital than do patients without cardiogenic shock. However, the prognosis for patients with cardiogenic shock who are in the hospital has improved considerably in recent years. This improvement may be due to the increasingly aggressive strategies of intervention used or to changes in the natural history of shock, with fewer cases that subsequently result in death identified early in the course of the illness. In our unadjusted analyses, patients who survived cardiogenic shock were significantly more likely than those who died from it to have received beneficial therapies for cardiac disease, and they were more likely to have received aggressive treatment for acute coronary disease through interventional approaches. The findings suggest that these therapies have a beneficial effect on the survival of patients with acute myocardial infarction in whom cardiogenic shock has developed.

The use of intraaortic balloon counterpulsation in patients with cardiogenic shock has been shown to result in initially favorable clinical and hemodynamic responses; however, in the majority of studies in which this intervention was used, death was merely delayed. ${ }^{26,27}$ A number of nonrandomized studies suggest that percutaneous transluminal coronary angioplasty improves short-term survival among patients with cardiogenic shock, with survival contingent on the successful establishment of coronary reperfusion. ${ }^{14,15,28,29}$ Uncontrolled studies of bypass grafting show that this therapy improves short-term survival among patients with cardiogenic shock when they are treated soon after shock has developed. 30,31

Although thrombolytic therapy has consistently been shown to decrease mortality after acute myocardial infarction, ${ }^{32,33}$ no large, randomized, controlled trial has found that the use of clot-lysing therapy reduces the incidence of cardiogenic shock or improves survival after cardiogenic shock has developed. In GUSTO-1, 56 percent of all patients with cardiogenic shock died in the hospital, regardless of the thrombolytic regimen used. ${ }^{22}$ Nonetheless, it has been hypothesized that the early resumption of coronary blood flow in the infarct-affected artery by means of thrombolytic agents, percutaneous transluminal coronary angioplasty or coronary-artery bypass grafting supported by intraaortic balloon counterpulsation, or both, reduces the size of the infarct, decreases the risk of ongoing myocardial ischemia and left ventricular dysfunction, and improves survival among patients with cardiogenic shock. ${ }^{12,28}$ Recent analyses from the GUSTO-1 trial suggest that the use of a more aggressive revascularization strategy in patients with cardiogenic shock, after initial treatment with a thrombolytic regimen, is associated with a reduction in short-term mortality even after control for differences that affected the selection of treatment. ${ }^{34,35}$
The current study was carried out in a well-defined metropolitan area whose sociodemographic and economic characteristics reflect those of the U.S. population with the exception of race (the vast majority of the residents of metropolitan Worcester are white). The strengths of this study are its large sample; its population-based design, which enhances the generalizability of the findings; and the inclusion of all hospitals in the area. The study has several limitations, however. Specific therapies for patients with cardiogenic shock were not determined by a standardized study protocol but, rather, by the many individual physicians practicing at the hospitals. In addition, because of the methods of data collection and the recording of data from hospitals, it was difficult to determine whether a particular drug or procedure was used before or after cardiogenic shock developed; therefore, we did not control for the use of these therapies in additional multivariable-adjusted regression analyses. Finally, in analyzing the declining mortality associated with cardiogenic shock over time, one must be careful in interpreting the multivariableadjusted odds of dying, because they may overestimate the actual risk ratio calculated in cohort studies. ${ }^{36}$

The rate of use of thrombolytic agents and interventional procedures was lower in our communitywide observational study than in other studies that have focused specifically on the use of targeted interventions in patients with cardiogenic shock. ${ }^{12,28,31}$ Most patients failed to receive clot-lysing therapy because of prolonged delays in seeking medical care. An extended prehospital delay may be associated with more extensive myocardial necrosis and a greater risk of shock. Patients with cardiogenic shock may also be more likely to be excluded from clinical trials of new approaches to treating acute myocardial infarction that are ultimately found to be beneficial. ${ }^{37}$

As evidenced by the results of this study, cardiogenic shock continues to develop at a relatively high rate after acute myocardial infarction, even though thrombolytic agents and interventional procedures are being used more. The in-hospital death rate among patients with this complication remains high. Until the results of a multicenter, randomized trial that has been designed to study the effect of aggressive interventional approaches on the incidence and prognosis of cardiogenic shock in association with acute myocardial infarction are published, ${ }^{12,38}$ it remains important to study trends in incidence and prognosis. This is particularly crucial if the use of surgical interventions and myocardial-reperfusion strategies continues to increase.

Supported by a grant (R01 HL35434) from the National Heart, Lung, and Blood Institute.

We are indebted to the departments of cardiology, administration, and medical records of the participating metropolitan Worcester hospitals for their cooperation. 


\section{REFERENCES}

1. Califf RM, Bengston JR. Cardiogenic shock. N Engl J Med 1994;330: 1724-30.

2. Domanski MJ, Topol EJ. Cardiogenic shock: current understandings

and future research directions. Am J Cardiol 1994;74:724-6.

3. Killip T. Cardiogenic shock complicating myocardial infarction. J Am Coll Cardiol 1989;14:47-8.

4. Scheidt S, Ascheim R, Killip T III. Shock after acute myocardial infarction: a clinical and hemodynamic profile. Am J Cardiol 1970;26:556-64.

5. Gheorghiade M, Anderson J, Rosman H, et al. Risk identification at the time of admission to coronary care unit in patients with suspected myocardial infarction. Am Heart J 1988;116:1212-7.

6. Kuhn LA. The treatment of cardiogenic shock. I. The nature of cardiogenic shock. Am Heart J 1967;74:578-81.

7. Kobayashi M, Niitani H, Hasegawa M, Goto H, Kuwahara K. Effect of medical treatment of acute myocardial infarction in coronary care unit study on its effect mainly on the cases with complication. Jpn Circ J 1984; 48:650-8.

8. Goldberg R, Szklo M, Tonascia JA, Kennedy HL. Time trends in prognosis of patients with myocardial infarction: a population-based study. Johns Hopkins Med J 1979;144:73-80.

9. Hands ME, Rutherford JD, Muller JE, et al. The in-hospital development of cardiogenic shock after myocardial infarction: incidence, predictor of occurrence, outcome and prognostic factors: the MILIS Study Group. J Am Coll Cardiol 1989;14:40-6.

10. Leor J, Goldbourt U, Reicher-Reiss H, Kaplinsky E, Behar S. Cardiogenic shock complicating acute myocardial infarction in patients without heart failure on admission: incidence, risk factors, and outcome. Am J Med 1993;94:265-73

11. Goldberg RJ, Gore JM, Alpert JS, et al. Cardiogenic shock after acute myocardial infarction: incidence and mortality from a community-wide perspective, 1975 to 1988. N Engl J Med 1991;325:1117-22.

12. Hochman JS, Boland J, Sleeper LA, et al. Current spectrum of cardiogenic shock and effect of early revascularization on mortality: results of an international registry. Circulation 1995;91:873-81.

13. Lee L, Bates ER, Pitt B, Walton JA, Laufer N, O'Neill WW. Percutaneous transluminal coronary angioplasty improves survival in acute myocardial infarction complicated by cardiogenic shock. Circulation 1988;78: 1345-51.

14. Hibbard MD, Holmes DR Jr, Bailey KR, Reeder GS, Bresnahan JF, Gersh BJ. Percutaneous transluminal coronary angioplasty in patients with cardiogenic shock. J Am Coll Cardiol 1992;19:639-46.

15. Lee L, Erbel R, Brown TM, Laufer N, Meyer J, O’Neill WW. Multicenter registry of angioplasty therapy of cardiogenic shock: initial and long-term survival. J Am Coll Cardiol 1991;17:599-603.

16. Cheitlin MD. The aggressive war on acute myocardial infarction: is the blitzkrieg strategy changing? JAMA 1988;260:2894-6.

17. Goldberg RJ, Gore JM, Alpert JS, Dalen JE. Incidence and case fatality rates of acute myocardial infarction (1975-1984): the Worcester Heart Attack Study. Am Heart J 1988;115:761-7.

18. Goldberg RJ, Gorak EJ, Yarzebski J, et al. A communitywide perspective of gender differences and temporal trends in the incidence and survival rates after acute myocardial infarction and out-of-hospital deaths caused by coronary heart disease. Circulation 1993;87:1947-53.

19. Goldberg RJ, Gore JM, Alpert JS, Dalen JE. Recent changes in attack and survival rates of acute myocardial infarction (1975 through 1981): the Worcester Heart Attack Study. JAMA 1986;255:2774-9.

20. Pagley PR, Yarzebski J, Goldberg RJ, et al. Gender differences in the treatment of patients with acute myocardial infarction: a multi-hospital, community-based perspective. Arch Intern Med 1993;153:625-9.

21. Chiriboga DE, Yarzebski J, Goldberg RJ, et al. A community-wide perspective of gender differences and temporal trends in the use of diag nostic and revascularization procedures for acute myocardial infarction. Am J Cardiol 1993;71:268-73.

22. Holmes DR Jr, Bates ER, Kleiman NS, et al. Contemporary reperfusion therapy for cardiogenic shock: the GUSTO-I trial experience. J Am Coll Cardiol 1995;26:668-74

23. Gurwitz JH, Goldberg RJ, Chen Z, Gore JM, Alpert JS. Recent

trends in hospital mortality of acute myocardial infarction - the Worcester Heart Attack Study: have improvements been realized for all age groups? Arch Intern Med 1994;154:2202-8.

24. Goldberg RJ. Declining out-of-hospital sudden coronary death rates: additional pieces of the epidemiologic puzzle. Circulation 1989;79:136973

25. Peterson ED, Shaw LJ, Califf RM. Risk stratification after myocardial infarction. Ann Intern Med 1997;126:561-82.

26. Scheidt $S$, Wilner G, Mueller $H$, et al. Intra-aortic balloon counterpulsation in cardiogenic shock: report of a co-operative clinical trial. $\mathrm{N} \mathrm{Engl}$ J Med 1973;288:979-84.

27. DeWood MA, Notske RN, Hensley GR, et al. Intraaortic balloon counterpulsation with and without reperfusion for myocardial infarction shock. Circulation 1980;61:1105-12.

28. Gacioch GM, Ellis SG, Lee L, et al. Cardiogenic shock complicating acute myocardial infarction: the use of coronary angioplasty and the integration of the new support devices into patient management. J Am Coll Cardiol 1992;19:647-53.

29. O'Neill WW. Angioplasty therapy of cardiogenic shock: are randomized trials necessary? J Am Coll Cardiol 1992;19:915-7.

30. Bolooki H. Emergency cardiac procedures in patients in cardiogenic shock due to complications of coronary artery disease. Circulation 1989; 79:Suppl I:I-137-I-148

31. Bengtson JR, Kaplan AJ, Pieper KS, et al. Prognosis in cardiogenic shock after acute myocardial infarction in the intervention era. J Am Coll Cardiol 1992;20:1482-9.

32. Gruppo Italiano per lo Studio della Streptochinasi nell'Infarto Miocardico (GISSI). Effectiveness of intravenous thrombolytic treatment in acute myocardial infarction. Lancet 1986;1:397-402.

33. Van de Werf $F$, Arnold AER. Intravenous tissue plasminogen activator and size of infarct, left ventricular function, and survival in acute myocardial infarction. BMJ 1988;297:1374-9.

34. Holmes DR Jr, Califf RM, Van de Werf F, et al. Difference in countries' use of resources and clinical outcome for patients with cardiogenic shock after myocardial infarction: results from the GUSTO trial. Lancet 1997;349:75-8

35. Berger PB, Holmes DR Jr, Stebbins AL, Bates ER, Califf RM, Topol EJ. Impact of an aggressive invasive catheterization and revascularization strategy on mortality in patients with cardiogenic shock in the Global Utilization of Streptokinase and Tissue Plasminogen Activator for Occluded Coronary Arteries (GUSTO-I) trial: an observational study. Circulation 1997;96:122-7.

36. Zhang J, Yu KF. What's the relative risk? A method of correcting the odds ratio in cohort studies of common outcomes. JAMA 1998;280:1690-1. 37. Col NF, Gurwitz JH, Alpert JS, Goldberg RJ. Frequency of inclusion of patients with cardiogenic shock in trials of thrombolytic therapy. Am J Cardiol 1994;73:149-57.

38. Moscucci M, Bates ER. Cardiogenic shock. Cardiol Clin 1995;13:391406. 